\title{
THE
}

2004

\section{Multiple Versus Single Antipsychotic Agents for Hospitalized Psychiatric Patients: Case-Control Study of Risks Versus Benefits}

\author{
Franca Centorrino \\ L. Gören \\ University of Rhode Island, jgoren@challiance.org \\ John Hennen \\ Paola Salvatore \\ James P. Kelleher
}

See next page for additional authors

Follow this and additional works at: https://digitalcommons.uri.edu/php_facpubs

Terms of Use

All rights reserved under copyright.

\section{Citation/Publisher Attribution}

Centorrino, F., Gören, J. L., Hennen, J., Salvatore, P., Kelleher, J. P., \& Baldessarini, R. J. (2004). Multiple Versus Single Antipsychotic Agents for Hospitalized Psychiatric Patients: Case-Control Study of Risks Versus Benefits. American Journal of Psychiatry, 161(4), 700-706. doi: 10.1176/appi.ajp.161.4.700 Available at: http://dx.doi.org/10.1176/appi.ajp.161.4.700

This Article is brought to you for free and open access by the Pharmacy Practice at DigitalCommons@URI. It has been accepted for inclusion in Pharmacy Practice Faculty Publications by an authorized administrator of DigitalCommons@URI. For more information, please contact digitalcommons-group@uri.edu. 
Authors

Franca Centorrino, L. Gören, John Hennen, Paola Salvatore, James P. Kelleher, and Ross J. Baldessarini

This article is available at DigitalCommons@URI: https://digitalcommons.uri.edu/php_facpubs/65 


\section{Multiple Versus Single Antipsychotic Agents for Hospitalized Psychiatric Patients: Case-Control Study of Risks Versus Benefits}

\author{
Franca Centorrino, M.D. \\ Jessica L. Goren, Pharm.D. \\ John Hennen, Ph.D. \\ Paola Salvatore, M.D. \\ James P. Kelleher, M.D. \\ Ross J. Baldessarini, M.D.
}

\begin{abstract}
Objective: Since use of multiple drugs to treat psychiatric patients is increasing, and research on this practice is rare, the authors carried out a retrospective case-control study of multiple versus single antipsychotic treatment in psychiatric inpatients.

Method: Inpatient treatment groups re-
ceiving either antipsychotic monotherapy
or polytherapy were matched in terms of
age, sex, diagnostic category, and admis-
sion clinical ratings (Global Assessment of
Functioning [GAF] and Clinical Global
Impression [CGI]), which yielded 70 sub-
ject pairs. They were compared in terms
of total chlorpromazine-equivalent daily
dose, changes in total daily dose, length
of hospitalization, incidence of adverse
effects, and changes in clinical ratings (CGI,
GAF, Positive and Negative Syndrome
\end{abstract}

Scale score) between admission and discharge.

Results: Initial doses were closely similar at admission for both treatment groups, but the median total final antipsychotic dose was $78 \%$ higher for those receiving antipsychotic polytherapy versus monotherapy. Also, median length of stay in the hospital was $55 \%$ (8.5 days) longer, and risk of adverse effects was $56 \%$ higher with polytherapy, whereas clinical improvement scores were similar (within 11\%) for both treatments.

Conclusions: Short-term treatment with multiple antipsychotics was associated with major increases in drug exposure, adverse events, and time in the hospital but with no apparent gain in clinical benefit. These findings require further testing in controlled prospective studies.

(Am J Psychiatry 2004; 161:700-706)

A medicine...should always be presumed to be hurtful (1).

$O$ imultaneous use of multiple psychotropic drugs, be they similar or dissimilar, by patients with major psychiatric disorders is a very common clinical practice (2). Evidence that such treatment is becoming increasingly common includes a study of 178 bipolar disorder patients with psychotic features hospitalized at the U.S. National Institute of Mental Health, in which the proportion simultaneously given three or more psychotropic medicines, including antipsychotics, increased from 3.3\% in 1974-1979 to $44 \%$ in $1990-1995$ (3). In that sample, length of hospitalization rose with the number of medicines prescribed at discharge, possibly as a reflection of illness severity or treatment unresponsiveness, whereas changes in clinical ratings were unrelated to drug count (3). Recent studies have found simultaneous use of more than one antipsychotic agent in $25 \%-50 \%$ of hospitalized psychiatric patients (4-9). In an analysis of recent antipsychotic drug use among hospitalized patients, we found prescribing patterns that were consistent with the preceding reports in that multiple antipsychotics were given to $43 \%$ of patients in 1998 (compared with 6\% in 1993 and $2 \%$ in 1989), with a corresponding $46 \%$ increase in estimated chlorpromazine-equivalent total daily dose of antipsychotic agents between 1989 and 1998 (10).

This trend toward polytherapy with antipsychotics and other psychotropic medicines may reflect availability of a growing number of pharmacologically varied drugs approved by the Food and Drug Administration (FDA) with demonstrated efficacy in major psychiatric disorders (11). Among antipsychotic drugs, combinations of newer atypical agents with older neuroleptics appear to be especially common (10). With chronically ill psychotic patients, who typically show only limited benefits of treatment, simultaneous use of more than one antipsychotic agent may reflect hopes for greater effectiveness of treatment involving drugs with somewhat dissimilar actions. However, such practices lack compelling empirical evidence of superior effectiveness, might compromise safety and tolerability, and may increase the cost of care.

Potential clinical benefits associated with the use of multiple antipsychotics have been considered in a few reports, mostly involving small case series without control subjects (12-20). In such studies, combinations of risperidone with clozapine (12-14), loxapine with clozapine (15), olanzapine with clozapine (16), and risperidone with olanzapine (17), as well as various combinations of older 
and modern antipsychotics (18-20), were suggested to have favorable effects on the basis of clinical observations of benefits not found with previous standard monotherapies. However, these open, uncontrolled clinical experiences, although provocative, do not prove that such combinations are clinically superior than or as equally well tolerated as vigorously applied monotherapies, including the use of older and much less expensive neuroleptics. A rare placebo-controlled, double-blind trial found clinical benefit in adding sulpiride over placebo to ongoing treatment with clozapine; however, this trial was small $(\mathrm{N}=28)$ and did not include a control condition involving increased doses of clozapine alone (21).

Tolerability and potential risks of adverse effects associated with antipsychotic polytherapy have received particularly limited research attention. In one report, increases in only relatively minor adverse effects, such as excess sedation, were found with several combinations of newer and older antipsychotic agents (22). However, a prospective, 10 -year follow-up study found that overall mortality rates among 88 hospitalized patients diagnosed with schizophrenia inexplicably were increased by two- to threefold in association with antipsychotic polytherapy (23).

The evidently growing contemporary prevalence of antipsychotic polytherapy calls for studies of the clinical effects, medical risks, and economic costs of concurrent use of multiple antipsychotic drugs. Accordingly, we now report on an analysis of consecutive hospitalized patients treated with more than one antipsychotic drug at the same time and compared this group with a matched group of similar patients treated with only one antipsychotic drug at any time during hospitalization.

\section{Method}

We screened the medical records of all inpatients with DSM-IV psychotic disorders admitted to McLean Hospital during a 3month period (March-May) in 1998. Computerized prescription drug records were used to identify "cases" given two or more antipsychotic drugs simultaneously for at least 3 consecutive days during the index hospitalization, with no exclusion criteria applied. We then matched each case with a "comparator" subject hospitalized within the same 3 months but treated with only one antipsychotic drug at one time. Matching was by sex, DSM-IV category (schizophrenia or schizophreniform disorder, bipolar disorder with psychotic features, or other disorders), age (within 5 years), and illness severity at admission as estimated by two retrospective psychiatric ratings: Clinical Global Impression (CGI) (24) (within 1 point) and Global Assessment of Functioning (GAF) (DSM-IV, p. 32) (within 5 points).

We determined the initial, maximum, and final or discharge total daily antipsychotic dose for each subject and recorded the days of use of each agent. In addition, the percentage increase from the initial to maximum daily dose was computed as a within-subject index of antipsychotic dosing. Reported doses (mg/day) were based on conversion to the approximate daily chlorpromazine equivalent, using recently developed conversion factors reported elsewhere (10) for all FDA-approved antipsychotic agents.

Based on independent assessments of data provided in medical records by two clinician-investigators (J.L.G., P.S.), estimated
TABLE 1. Demographic and Clinical Characteristics of Matched Psychiatric Inpatients Receiving Multiple or Single Antipsychotic Treatment

\begin{tabular}{|c|c|c|c|c|}
\hline \multirow[t]{2}{*}{ Selection Factors } & \multicolumn{2}{|c|}{$\begin{array}{c}\text { Patients Receiving } \\
\text { Antipsychotic } \\
\text { Polytherapy } \\
(\mathrm{N}=70)\end{array}$} & \multicolumn{2}{|c|}{$\begin{array}{l}\text { Patients Receiving } \\
\text { Antipsychotic } \\
\text { Monotherapy } \\
(\mathrm{N}=70)\end{array}$} \\
\hline & $\mathrm{N}$ & $\%$ & $\mathrm{~N}$ & $\%$ \\
\hline \multicolumn{5}{|l|}{$\operatorname{Sex}^{\mathrm{a}}$} \\
\hline Women & 43 & 61.4 & 43 & 61.4 \\
\hline Men & 27 & 38.6 & 27 & 38.6 \\
\hline \multicolumn{5}{|l|}{ Diagnosis $^{\mathrm{a}}$} \\
\hline Bipolar disorder & 18 & 25.7 & 18 & 25.7 \\
\hline Psychotic disorders & 44 & 62.9 & 44 & 62.9 \\
\hline \multirow[t]{2}{*}{ Other disorders } & 8 & 11.4 & 8 & 11.4 \\
\hline & Mean & SD & Mean & SD \\
\hline \multicolumn{5}{|l|}{ Age (years) } \\
\hline Onset & $22.7^{\mathrm{b}}$ & 6.2 & 26.9 & 13.1 \\
\hline Admission ${ }^{\mathrm{a}}$ & 40.5 & 14.4 & 41.9 & 14.8 \\
\hline \multicolumn{5}{|l|}{ Previous illness } \\
\hline Hospitalizations & 5.5 & 4.1 & 5.3 & 5.4 \\
\hline Years of illness & 17.3 & 15.1 & 15.1 & 11.6 \\
\hline \multicolumn{5}{|l|}{ Baseline illness ratings } \\
\hline $\mathrm{CGl}^{\mathrm{a}}$ & 5.8 & 0.8 & 5.8 & 0.8 \\
\hline $\mathrm{GAF}^{\mathrm{a}}$ & 29.2 & 8.4 & 32.0 & 10.1 \\
\hline \multicolumn{5}{|l|}{$\begin{array}{l}\text { Positive and Negative } \\
\text { Syndrome Scale }\end{array}$} \\
\hline Total & 39.4 & 10.9 & 41.4 & 13.6 \\
\hline Positive & 23.3 & 8.0 & 23.6 & 8.5 \\
\hline Negative & 16.0 & 7.5 & 17.8 & 10.2 \\
\hline
\end{tabular}

${ }^{a}$ Factor used to match subjects in the treatment groups.

${ }^{b}$ Significantly different from the onset age of patients receiving antipsychotic monotherapy $(z=2.19, p=0.03)$.

baseline and discharge ratings for the GAF, CGI, and Positive and Negative Syndrome Scale (25) were made (with consensus ratings in cases of discrepancies) independent of knowledge of dosing. Percentage changes in the three clinical assessments between hospital admission and discharge were computed for each subject. We also defined three subscales from the Positive and Negative Syndrome Scale to identify relationships of specific symptom complexes in cases versus comparators. These ad hoc subscales were: disorganization (Positive and Negative Syndrome Scale items P2, N5, N7, G10, G11, G12), anxiety/agitation (P4, P7, G3, G4, G14), and paranoia/hypervigilance (P6, G8, G9, G16).

Also from medical records data, we determined prior hospitalization count, approximate age at onset of the primary psychiatric diagnosis, length of stay (days) for the index hospitalization, and the type and number of all other psychotropic drugs used. We identified adverse effects recorded during hospitalization, by category, including neurological and general medical events, determined if they were present at admission or emerged during hospitalization, and supplemented this information with incident use of drugs employed to manage extrapyramidal side effects (anticholinergics and lipophilic beta-blockers in the absence of a cardiovascular indication). Both total adverse events and percentage of patients with at least one adverse event were recorded.

We examined factors and clinical outcomes associated with the treatment classification (antipsychotic polytherapy versus monotherapy) other than those used to match the groups, with particular attention to contrasting antipsychotic doses (initial, maximum, and final), incidence and types of medically adverse effects, hospital length of stay, and improvements in clinical ratings. Contrasts between antipsychotic polytherapy cases and monotherapy comparators were carried out by using conditional logistic regression methods for binary outcomes (adverse effects), negative binomial regression for prior hospitalization counts, generalized least- 
FIGURE 1. Initial, Maximum, and Final ChlorpromazineEquivalent Doses for Matched Psychiatric Inpatients Receiving Multiple or Single Antipsychotic Treatment

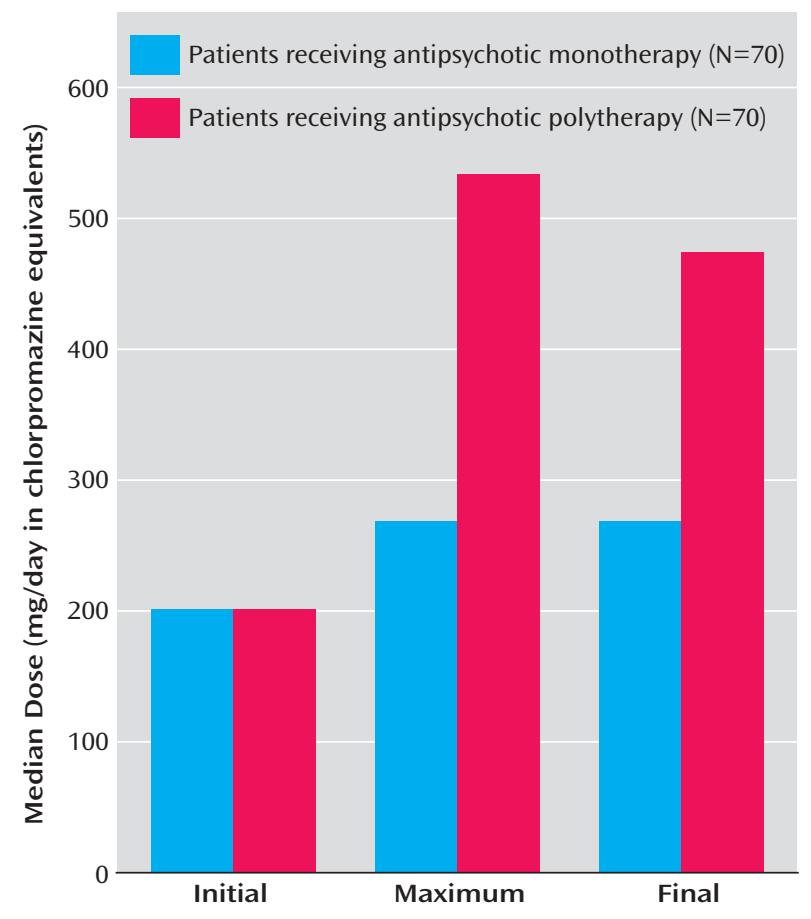

squares regression with binomial family and log-link to estimate relative risk for adverse effects, and generalized least-squares regression methods (Gaussian family) for the remaining outcomes (changes in clinical rating scale scores from baseline, chlorpromazine-equivalent daily doses, and length of stay). Regression analyses included adjustment for clustering on matched pairs. For selected contrasts, several covariates were considered in additional modeling; these included sex, current age, diagnostic category, number of previous hospitalizations, and baseline CGI and GAF ratings. Postmodeling chi-square tests were carried out for selected contrasts. For some bivariate comparisons involving continuous measures, Spearman rank correlations $\left(r_{s}\right)$ were used. Chlorpromazine-equivalent dose and length of stay data were positively skewed (few patients with unusually high doses and long hospitalizations) and so were log-normalized before analysis. We checked modeling fits using partial-residual plotting methods. Robust estimates of standard errors were obtained when feasible.

Averaged continuous data are reported as means with standard deviations, except for the skewed dose and length of stay data, for which medians and standard deviations are reported. Statistical significance required two-tailed $\mathrm{p}<0.05$. Analyses employed Stata (Stata Corp, College Station, Tex.) and Statview-5 (SAS Corp., Cary, N.C.) microcomputer programs.

\section{Results}

A total of 140 inpatients in 70 matched pairs were studied. Matching of polytherapy cases and monotherapy comparators was based on current age, sex, diagnostic category, and initial GAF and CGI ratings, but not other factors, all of which are summarized in Table 1. Of all factors considered, the only significant difference found was that patients receving antipsychotic polytherapy were on average 4.2 years younger at illness onset than those receiving antipsychotic monotherapy (Table 1). On two severity indicators not used in matching, Positive and Negative Syndrome Scale scores (including total, positive, and negative scores) and the number of prior hospitalizations, the treatment groups did not differ at baseline (Table 1). The total number of simultaneously administered psychotropic medicines ranged from one to seven, with polytherapy cases averaging 4.29 medications $(\mathrm{SD}=1.23)$ and monotherapy comparators averaging $3.47(\mathrm{SD}=1.46)$. This difference, while large, basically reflects the circumstance that comparator subjects were prescribed one antipsychotic agent, while all polytherapy cases received at least two such drugs at the same time, and six received three different antipsychotic agents at some point during the inpatient stay.

\section{Antipsychotic Doses}

In this sample of 140 patients hospitalized in 1998, 13 antipsychotic drugs were encountered: olanzapine $(46.4 \%$ of cases), quetiapine (33.6\%), risperidone (19.3\%), haloperidol $(16.4 \%)$, perphenazine $(16.4 \%)$, clozapine $(6.4 \%)$, thioridazine $(4.3 \%)$, chlorpromazine (3.6\%), fluphenazine $(3.6 \%)$, thiothixene $(2.9 \%)$, and loxapine, promethazine, and trifluoperazine (3.6\% total). The overlap (total $>100 \%$ of cases) was due to polytherapy or changes in medication during hospitalization. A large fraction $(88.6 \%$ [ $\mathrm{N}=124$ of 140]) of all study patients received at least one atypical antipsychotic. The most frequently occurring combinations of antipsychotic medicines were olanzapine with haloperidol $(\mathrm{N}=10)$, olanzapine with quetiapine $(\mathrm{N}=6)$, and olanzapine with risperidone $(\mathrm{N}=6)$. Except for one agent, quetiapine, polytherapy cases did not differ from monotherapy comparator patients in the types of antipsychotics used. Quetiapine was used more frequently among those receiving antipsychotic polytherapy $(44.3 \%$ versus $22.9 \%)$ (ratio=1.94; $\mathrm{z}=2.63, \mathrm{p}=0.009$ ).

Final total daily doses were higher in subjects diagnosed with idiopathic psychotic disorders ( $\mathrm{N}=44$ pairs; median dose [in chlorpromazine equivalents] $=475 \mathrm{mg} /$ day $[\mathrm{SD}=$ 402]) than in those with bipolar disorder with psychotic features ( $\mathrm{N}=18$ pairs; median dose $=267 \mathrm{mg}$ [SD=262]) or those with other miscellaneous diagnoses ( $\mathrm{N}=8$ pairs; median dose=197 mg [SD=387]). Of these dose contrasts, only schizophrenia versus miscellaneous diagnosis subjects differed significantly $(\mathrm{z}=3.83, \mathrm{p}<0.001)$. Final total chlorpromazine-equivalent doses were somewhat higher in men than in women (median=283 $\mathrm{mg} /$ day $[\mathrm{SD}=393$ ] versus median= $267 \mathrm{mg} /$ day [SD=262], respectively) $(\mathrm{z}=2.57, \mathrm{p}=0.01)$. After the subjects were divided on the basis of age at admission (median split at 38 years), older subjects received nonsignificantly lower final chlorpromazine-equivalent doses than younger patients (median dose $=334 \mathrm{mg} /$ day $[\mathrm{SD}=378]$ versus median=401 $\mathrm{mg} /$ day $[\mathrm{SD}=385])(\mathrm{z}=0.39, \mathrm{p}=0.70)$.

As seen in Figure 1, the initial daily doses of antipsychotic drugs did not differ between the antipsychotic 
TABLE 2. Treatment Characteristics of Matched Psychiatric Inpatients Receiving Multiple or Single Antipsychotic Treatment

\begin{tabular}{|c|c|c|c|c|c|c|c|}
\hline \multirow[b]{2}{*}{ Treatment Characteristic } & \multirow{2}{*}{\multicolumn{2}{|c|}{$\begin{array}{l}\text { Patients Receiving } \\
\text { Antipsychotic } \\
\text { Polytherapy }(\mathrm{N}=70)\end{array}$}} & \multirow{2}{*}{\multicolumn{2}{|c|}{$\begin{array}{l}\text { Patients Receiving } \\
\text { Antipsychotic } \\
\text { Monotherapy }(\mathrm{N}=70)\end{array}$}} & \multicolumn{3}{|c|}{ Analysis } \\
\hline & & & & & \multirow[t]{2}{*}{ Ratio } & \multirow[t]{2}{*}{$\mathrm{z}$} & \multirow[t]{2}{*}{$\mathrm{p}$} \\
\hline & Median & SD & Median & SD & & & \\
\hline \multicolumn{8}{|c|}{ Antipsychotic dose (mg/day in chlorpromazine equivalents) } \\
\hline Initial & 200 & 326 & 201 & 287 & 0.99 & 0.92 & 0.36 \\
\hline Maximum & 534 & 425 & 268 & 308 & 1.99 & 4.69 & $<0.001$ \\
\hline Final & 475 & 413 & 267 & 315 & 1.78 & 4.63 & $<0.001$ \\
\hline Increase from initial dose (\%) & 461 & 752 & 92 & 187 & 5.01 & 4.64 & $<0.001^{\mathrm{a}}$ \\
\hline \multirow[t]{2}{*}{ Hospitalization (days) } & 24.0 & 31.1 & 15.5 & 16.2 & 1.55 & 3.90 & $<0.001^{\mathrm{a}}$ \\
\hline & Mean & SD & Mean & SD & & & \\
\hline Other psychotropic agents (number/subject) ${ }^{b}$ & 2.29 & 1.23 & 2.47 & 1.46 & 0.93 & -0.80 & 0.42 \\
\hline \multicolumn{8}{|l|}{ Change in clinical ratings (\%) } \\
\hline $\mathrm{CGI}$ & -28.2 & 14.0 & -25.3 & 15.0 & 1.11 & -1.22 & 0.22 \\
\hline GAF & -71.0 & 59.8 & -66.7 & 69.1 & 1.06 & 0.52 & 0.60 \\
\hline \multirow[t]{2}{*}{ Positive and Negative Syndrome Scale score } & -37.0 & 36.6 & -41.4 & 31.5 & 0.89 & 0.70 & 0.49 \\
\hline & $\mathrm{N}$ & $\%$ & $\mathrm{~N}$ & $\%$ & & & \\
\hline Adverse effects ${ }^{c}$ & 28 & 40.0 & 18 & 25.7 & 1.56 & 1.64 & $0.11^{\mathrm{a}}$ \\
\hline
\end{tabular}

${ }^{a}$ After adjustment for sex, age, diagnosis, CGI and GAF ratings at admission, and number of previous hospitalizations, the following betweengroup differences were found: log-\% increase in antipsychotic dose $(z=4.19, p<0.001)$, log-days in hospital $(z=4.08, p<0.001)$, and risk of adverse effects $(z=1.82, p<0.07)$.

${ }^{\mathrm{b}}$ Includes antidepressants, anxiolytics, sedatives, and mood stabilizers.

c Patients who either had one or more adverse effects or were given additional medication for extrapyramidal symptoms.

polytherapy and monotherapy groups, but the maximum and final total antipsychotic doses were substantially greater in polytherapy cases $(99 \%$ and $78 \%$ higher, respectively) (Table 2). Moreover, the corresponding increase over initial doses during hospitalization was 5.0 times greater for polytherapy cases (461\%) than the monotherapy comparison patients (92\%). After adjusting for sex, age, diagnosis, admission CGI and GAF ratings, and number of previous hospitalizations, the log-\% increase in dose of antipsychotics remained significantly different between polytherapy and monotherapy subjects (Table 2).

An important consideration was that the total number of nonantipsychotic psychotropic agents per subject (about two) did not differ between antipsychotic polytherapy and monotherapy subjects (Table 2). Specifically, the proportion of cases versus comparators given sedativeanxiolytics ( $67.1 \%$ versus $72.9 \%)\left(\chi^{2}=0.54, \mathrm{df}=1, \mathrm{p}=0.46\right)$, anticonvulsants or lithium (60.0\% versus $60.0 \%)$, or antidepressants ( $55.7 \%$ versus $57.1 \%)\left(\chi^{2}=0.03, \mathrm{df}=1, \mathrm{p}=0.86\right)$ did not differ between those treated with antipsychotic polytherapy versus monotherapy.

\section{Risks of Adverse Effects}

Most of the adverse effects encountered involved movement disorders (bradykinesia or tremor, dyskinesia, akathisia), with a slight excess among polytherapy cases versus monotherapy comparators: $30.0 \%$ versus $24.3 \%$, respectively, had evidence of at least one type of extrapyramidal dysfunction $\left(\chi^{2}=0.58, \mathrm{df}=1, \mathrm{p}=0.45\right)$, whereas the incidence of all extrapyramidal dysfunctions was $42.9 \%$ versus $30.0 \%$ (relative risk $=1.43 ; \chi^{2}=2.50, \mathrm{df}=1, \mathrm{p}=0.11$ ). The incidence of at least one adverse effect or use of an ad- ditional agent to treat adverse extrapyramidal effects was somewhat higher among polytherapy cases than among monotherapy comparators ( $40.0 \%$ versus $25.7 \%$ ) (Table 2 ). After adjusting for sex, age, diagnosis, admission CGI and GAF ratings, and number of previous hospitalizations, the risk of extrapyramidal effects was nearly significantly greater with polytherapy. Use of agents intended to limit extrapyramidal dysfunctions (centrally active anticholinergics and beta-blockers) also was only slightly greater among polytherapy cases ( $32.9 \%$ versus $24.3 \%$ ).

Risk of reported side effects was correspondingly greater with higher antipsychotic final daily dose in the polytherapy cases, although not statistically significant. Patients with above-median chlorpromazine-equivalent doses experienced adverse effects significantly more frequently $(42.6 \%[\mathrm{~N}=29$ of 68$])$ than those given lower doses $(23.6 \%$ $[\mathrm{N}=17$ of 72$]$ ) (relative risk=1.81; $\mathrm{z}=2.15, \mathrm{p}<0.04)$. Risk of adverse effects also was clearly greater with typical neuroleptics $(48.5 \%$ [ $\mathrm{N}=33$ of 68$])$ than atypical antipsychotics $\left(30.6 \%[\mathrm{~N}=38\right.$ of 124$]$ ) (relative risk $=1.58 ; \chi^{2}=9.57, \mathrm{df}=1, \mathrm{p}=$ $0.002)$. Haloperidol was especially strongly associated with adverse effects: $56.5 \%$ ( $\mathrm{N}=13$ of 23 ) given this neuroleptic experienced adverse effects whereas only $28.2 \%$ ( $\mathrm{N}=33$ of 117) not exposed to haloperidol did (relative risk $=2.00 ; \mathrm{z}=$ $3.03, \mathrm{p}=0.002)$. Adverse effects were somewhat more common among women $(37.2 \%$ [ $\mathrm{N}=32$ of 86$])$ than men $(25.9 \%$ [ $\mathrm{N}=14$ of 54$]$ ) (relative risk=1.44; $\mathrm{z}=1.57, \mathrm{p}=0.12$ ) but did not vary with diagnostic category or age (data not shown).

\section{Length of Hospitalization}

Median length of stay during the index hospitalization (Table 2) was 55\% (8.5 days) longer in the polytherapy 
cases, and mean length of stay was $81 \%$ longer (34.3 versus 19.0 days) $(\mathrm{z}=3.90, \mathrm{p}<0.001)$. As expected, length of stay was longer with inferior admission GAF ratings overall $\left(\mathrm{r}_{\mathrm{s}}=\right.$ $-0.17, \mathrm{p}<0.05$ ) and with higher initial total scores on the Positive and Negative Syndrome Scale $\left(\mathrm{r}_{\mathrm{s}}=0.20, \mathrm{p}<0.02\right)$ but was uncorrelated with prior hospitalization count $\left(\mathrm{r}_{\mathrm{s}}=\right.$ 0.09, $\mathrm{p}=0.32$ ). Patients experiencing adverse effects spent on average about 4.5 days longer in hospital (26\% more days) than those without such complications (median length of $\mathrm{stay}=22.5$ days $[\mathrm{SD}=31.5]$ versus 17.0 days $[\mathrm{SD}=$ 22.2]) $(\mathrm{z}=1.91, \mathrm{p}=0.057)$. Length of stay was correlated with the maximum total antipsychotic daily dose $\left(r_{s}=0.17\right.$, $\mathrm{p}<0.05$ ) but not with the total number of psychotropic agents prescribed $\left(\mathrm{r}_{\mathrm{s}}=0.03, \mathrm{p}=0.73\right)$.

As suggested by the substantially larger mean than median length of stay in both treatment groups, some patients experienced unusually prolonged hospitalizations, which were most extreme (>100 days) in six polytherapy cases, considered statistical "outliers." When they and their matching monotherapy comparators were excluded, the finding of longer length of stay with polytherapy was sustained (median $=23.0$ days $[\mathrm{SD}=18.6$ ] versus 16.0 days [SD=12.8]) $(\mathrm{z}=3.50, \mathrm{p}<0.001)$. Moreover, after adjusting for sex, age, diagnosis, admission CGI and GAF ratings, and number of previous hospitalizations, the difference in loglength of stay between treatment groups was again sustained $(\mathrm{z}=4.08, \mathrm{p}<0.001)$.

\section{Clinical Changes}

In contrast to major excesses of maximum and final total antipsychotic doses, increases in antipsychotic total daily doses during hospitalization, hospital length of stay, and increased risks of adverse effects among the polytherapy cases, clinical ratings indicated very similar improvements between admission and discharge in both treatment groups. That is, percentage improvements in CGI and GAF ratings and Positive and Negative Syndrome Scale score all were within $11 \%$ between patients given single or multiple antipsychotic treatment (Table 2). After adjusting for sex, age, diagnosis, admission CGI and GAF score, and number of previous hospitalizations, the percentage change in Positive and Negative Syndrome Scale total score remained nonsignificant $(\mathrm{z}=0.76, \mathrm{p}=0.45)$. Moreover, changes in score on the positive or negative symptom subscales of the Positive and Negative Syndrome Scale and scores on the agitation, paranoia, and disorganization subscales all were similar between cases and comparators (data not shown). This similarity in clinical outcomes at hospital discharge following use of antipsychotic monotherapy and polytherapy may well reflect clinical decisions associated with adjusting treatment and time in the hospital to meet the requirements or responses of individual patients, and therefore is not surprising.

\section{Discussion}

Principal findings in this retrospective case-control comparison of psychiatric inpatients receiving antipsychotic monotherapy versus polytherapy, based on chart reviews, include the following points. 1) Maximum and final total chlorpromazine-equivalent antipsychotic doses, as well as the percentage increase in total daily doses during hospitalization, all were much higher among polytherapy patients. 2) Adverse effects occurred more frequently among polytherapy patients in association with higher total antipsychotic doses. 3) Hospitalization was much longer in antipsychotic polytherapy cases, particularly among patients with adverse effects. 4) Clinical outcomes, based on changes in CGI and GAF ratings and Positive and Negative Syndrome Scale score, did not differ between the matched treatment groups even after adjustment for age, sex, diagnosis, and initial CGI and GAF ratings. 5) Patients treated with antipsychotic monotherapy or polytherapy did not differ in the total number, or types, of other coadministered psychotropic agents. 6) Patients treated with antipsychotic polytherapy were 4.2 years younger at age at onset of illness than those treated with antipsychotic monotherapy. Too few patients were enrolled to make valid comparisons in outcomes associated with specific antipsychotic agents.

These findings are based on relatively brief inpatient treatment, when use of multiple agents of the same type is most likely to occur, and may not generalize to other circumstances (3-7). In this setting, several summary measures of clinical change during hospital stays lasting a median of 20 days $(\mathrm{SD}=25.9)$ did not differ between the antipsychotic polytherapy and monotherapy groups, whereas hospitalization was more than a week longer with polytherapy. The findings suggest a lack of obvious "benefit" of inpatient antipsychotic polytherapy in either superior clinical outcomes or shorter hospitalizations. Moreover, the relevant "costs" include a somewhat greater clinical burden of adverse effects, as well as the burden of inconvenience, life disruption, and substantial added financial costs associated with longer hospitalizations among the polytherapy cases as well as the higher drug acquisition costs involved. However, younger age at onset in the polytherapy group may represent a population that is more severely ill with a longer duration of illness and decreased medication responsiveness that may tend to encourage use of multiple antipsychotics.

It is somewhat reassuring that the clinical burden of adverse effects associated with antipsychotic polytherapy did not include severe or life-threatening adverse events, probably reflecting the relative safety of modern antipsychotic agents, as well as the limited exposure involved in this study of 140 patients during relatively brief hospitalizations (about 3,700 person-days). Nevertheless, some adverse effects associated with modern and traditional antipsychotic agents are not clinically trivial (e.g., acute 
and later extrapyramidal reactions, hypotension with falls and injuries or cardiovascular events, and weight gain with potentially increased risk of diabetes and other longterm cardiovascular risks). Some are even life-threatening (particularly the neuroleptic malignant syndrome and its apparent variants associated even with modern drugs [11, $26,27])$. While this study did not demonstrate a difference in serious adverse event rates, the number of participants was too low to detect a difference in such uncommon events. Accordingly, the safety of polytherapy remains to be proven.

The present findings accord very closely with those of at least one previous retrospective study (3), in which longer hospital stays and no clear evidence of differential clinical benefit were found in inpatients treated with multiple versus single psychotropic agents. Both investigations provide no evidence for substantial gains in benefit (such as superior improvements on standard clinical rating scales), and both indicate a pronounced association of psychotropic polytherapy with longer hospitalization. In addition, we report a nearly significant association of polytherapy with incidence of adverse effects and a correlation of adverse effects with extended length of stay. Yet, caution is required, since an appropriate interpretation of the findings exceeds the limits of the study design, particularly regarding the critical question of how to account for the longer hospitalizations associated with use of antipsychotic polytherapy. Nevertheless, since both adverse events and length of stay were closely correlated with the total daily doses of antipsychotics involved with polytherapy, it may be that extra days in the hospital, in part, are occasioned by management of iatrogenic side effects of the more complex treatment.

However, another plausible interpretation is that selection of antipsychotic polytherapy, and the associated longer hospitalization, may both represent responses to patients with less treatment-responsive conditions. Although subjects were closely matched on several baseline demographic and clinical variables, such factors would not necessarily predict individual responsiveness to treatment. The design of the present study does not allow determination of reasons for electing use of antipsychotic polytherapy nor does it avoid the issue through random assignment to treatment options. Also, clinical decisions about the degree of improvement required for discharge were uncontrolled, and the study method did not permit monitoring rates of improvement per time. These are all limitations inherent in the retrospective-naturalistic character of this investigation. Moreover, the study size is limited, even though much larger than several earlier case series involving combinations of antipsychotic drugs (4-7).

Future studies aimed at examining outcomes associated with multiple versus single medication treatment ideally should employ random assignment to fixed and comparable alternative regimens, with efforts to control additional adjunctive pharmacological and psychosocial components of treatment. Such requirements obviously are not easily attained, and such studies are not likely to receive support from the pharmaceutical industry, since multiple proprietary products are involved. A potentially informative, if scientifically less satisfactory, alternative to randomized studies would be large, prospective, naturalistic studies that systematically acquire data on dosing, adverse events, and clinical outcomes during the elective use of regimens of varied complexity.

In conclusion, there is currently no empirical foundation for the evidently increasingly common clinical practice of combining antipsychotic drugs in the short- or long-term treatment of severely mentally ill patients. The consequences of this practice, even in short-term use, are uncertain, although the present findings do not indicate a favorable cost/benefit relationship for hospitalized and mainly psychotic or manic patients. The unknown potential for adverse long-term iatrogenic effects of antipsychotic polytherapy, and of psychiatric polytherapy in general, is of even greater concern. The practice appears to arise from the unwarranted, and potentially harmful, presumption that greater benefits should be achieved with more aggressive treatment at minimal or no extra risk or cost.

Received Aug. 29, 2002; revision received Aug. 11, 2003; accepted Sept. 15, 2003. From the Department of Psychiatry and Neuroscience Program, Harvard Medical School, Boston; the Bipolar and Psychotic Disorders Clinic, McLean Hospital; and Northeastern University School of Pharmacy, Boston. Address reprint requests to Dr. Centorrino, Bipolar and Psychotic Disorders Clinic, North Belknap III, McLean Hospital, Belmont, MA 02478-9106; centorf@mcleanpo.mclean.org (e-mail).

Supported in part by an award from the Bruce J. Anderson Foundation and the McLean Private Donors Neuropsychopharmacology Research Fund (Dr. Baldessarini).

\section{References}

1. Holmes OW: Currents and counter-currents in medical science, in Medical Essays (1843-1892). Boston, Houghton Mifflin, 1911, pp 173-208

2. Ghaemi SN (ed): Polypharmacy in Psychiatry. New York, Marcel Dekker, 2002

3. Frye MA, Ketter TA, Leverich GS, Huggins T, Lantz C, Denicoff KD, Post RM: Increasing use of polypharmacotherapy for refractory mood disorders: 22 years of study. J Clin Psychiatry 2000; 61:9-15

4. Tohen M, Zarate CA Jr, Hennen J, Khalsa H-MK, Strakowski SM, Gebre-Medhin P, Salvatore P, Baldessarini RJ: The McLean-Harvard First-Episode Mania Study: prediction of recovery and first recurrence. Am J Psychiatry 2003; 160:2099-2107

5. Ereshevsky L: Pharmacologic and pharmacokinetic considerations in choosing an antipsychotic. J Clin Psychiatry 1999; 60(suppl 10):20-30

6. Procyshyn RM, Kennedy NB, Tse G, Thompson B: Antipsychotic polypharmacy: survey of discharge prescriptions from a tertiary care psychiatric institution. Can J Psychiatry 2001; 46: 334-339

7. Clark RE, Bartels SJ, Mellman TA, Peacock WJ: Recent trends in antipsychotic combination therapy of schizophrenia and schizoaffective disorder: implications for state mental health policy. Schizophr Bull 2002; 28:76-84 
8. Stahl SM: Selecting an atypical antipsychotic by combining clinical experience with guidelines from clinical trials. J Clin Psychiatry 1999; 60(suppl 10):31-41

9. Leslie DL, Rosenheck RA: Use of pharmacy data to assess quality of pharmacotherapy for schizophrenia in a national health care system: individual and facility predictors. Med Care 2001; 39:923-933

10. Centorrino F, Eakin M, Bahk W-M, Kelleher JP, Goren J, Salvatore P, Egli S, Baldessarini RJ: Inpatient antipsychotic drug use in 1998, 1993, and 1989. Am J Psychiatry 2002; 159:1932-1935

11. Baldessarini RJ, Tarazi FI: Drugs and the treatment of psychiatric disorders: antipsychotic and antimanic agents, in Goodman and Gilman's The Pharmacological Basis of Therapeutics, 10th ed. Edited by Hardman JG, Limbird LE, Molinoff PB, Ruddon RW, Gilman AG. New York, McGraw-Hill, 2001, pp 485-520

12. McCarthy RH, Terkelsen KG: Risperidone augmentation of clozapine. Pharmacopsychiatry 1995; 28:61-63

13. Henderson DC, Goff DC: Risperidone as an adjunct to clozapine therapy in chronic schizophrenics. J Clin Psychiatry 1996; 57: 395-397

14. Taylor CG, Flynn SW, Altman S: An open trial of risperidone augmentation of partial response to clozapine. Schizophr Res 2001; 48:155-158

15. Mowerman S, Siris SG: Adjunctive loxapine in a clozapine-resistant cohort of schizophrenic patients. Ann Clin Psychiatry 1996; 8:193-197

16. Gupta S, Sonnenberg SJ, Frank B: Olanzapine augmentation of clozapine. Ann Clin Psychiatry 1998; 10:113-115

17. Lerner V, Chudakova B, Kravets S, Polyakova I: Combined use of risperidone and olanzapine in the treatment of patients with resistant schizophrenia: preliminary case series report. Clin Neuropharmacol 2000; 23:284-286
18. Bacher NM, Kaup BA: Combining risperidone with standard neuroleptics for refractory schizophrenic patients (letter). Am J Psychiatry 1996; 153:137

19. Friedman J, Ault K, Powchik P: Pimozide augmentation for the treatment of schizophrenic patients who are partial responders to clozapine. Biol Psychiatry 1997; 42:522-523

20. Waring EW, Devin PG, Dewan V: Treatment of schizophrenia with antipsychotics in combination. Can J Psychiatry 1999; 44: 189-190

21. Shiloh R, Zemishlany Z, Aizenberg D, Radwan M, Schwartz B, Dorfman-Etrog P, Modai I, Khaikin M, Weizman A: Sulpiride augmentation in people with schizophrenia partially responsive to clozapine: a double-blind, placebo-controlled study. $\mathrm{Br}$ J Psychiatry 1997; 171:569-573

22. Potkin SG, Thyrum PT, Alva G, Bera R, Yeh C, Arvanitis LA: The safety and pharmacokinetics of quetiapine when coadministered with haloperidol, risperidone, or thioridazine. J Clin Psychopharmacol 2002; 22:121-130

23. Waddington JL, Youssef HA, Kinsella A: Antipsychotic polypharmacy and absence of adjunctive anticholinergics over the course of a 10-year prospective study. Br J Psychiatry 1998; 173:325-329

24. Guy W (ed): ECDEU Assessment Manual for Psychopharmacology: Publication ADM 76-338. Washington, DC, US Department of Health, Education, and Welfare, 1976, pp 218-222

25. Kay SR, Fiszbein A, Opler LA: The Positive and Negative Syndrome Scale (PANSS) for schizophrenia. Schizophr Bull 1987; 13:261-276

26. Tarsy D, Baldessarini RJ, Tarazi FI: Atypical antipsychotic agents: effects on extrapyramidal functions. CNS Drugs 2002; 16:23-45

27. Caroff SN, Mann SC, Campbell EC, Sullivan KA: Movement disorders associated with atypical antipsychotic drugs. J Clin Psychiatry 2002; 63(suppl 4):12-19 